\title{
Mulla Sadra's Theory of Substantial Motion
}

\author{
MOHAMMAD FANAEI ESHKEVARI, QOM
}

\section{Existence and Its Levels}

The subject of metaphysics is existence (wujud), or being qua being. According to Mulla Sadra existence is 'fundamental' ('asil) while quiddity (mahiyya) is abstracted from existence and hence is $i$ 'tibari, lacking in its own concrete objective reality. All that really exists in the universe are different levels of existence. Also according to his philosophy, existence is a single gradational reality that includes different levels. Existence becomes manifest in different forms and at various levels. Absolute existence is necessary being while limited and qualified existence is that of contingent beings. The quiddity of necessary being is nothing but its existence. Contingent beings are those from which a quiddity (other than mere existence) can be abstracted. Quiddity indicates the limits and determinations of existence. The existence of contingent beings is among the manifestations of the perfection of necessary being. In themselves, they have no independent existence and are dependent on necessary being for their coming into existence as well as for their continuance.

Necessary being is the absolute perfect being who is needless and lacks nothing. He possesses all that is possible and imaginable for him; thus, change does not take place in him. Therefore he is absolute 'actuality' (fi'liyyah). Immaterial beings, like angels, are also all that they can be. Consequently, though they are void of motion, they are not absolutely perfect. Material beings are such that they can be subject to change. They possess a characteristic known as 'potential' (bilquwwah). The current state of any material being is never to be considered as the determined state of it, for it can accept change and can be transformed into different states. For this very reason its future is somehow indefinite. On this basis, existence is classified into that which is absolute actuality and that which is potential. Of course, every being, including material being, consists of actuality. Material being is a combination of actuality and potentiality, and it is because of its being potential that it can accept different kinds of actuality. 
No doubt we witness numerous changes in the world. Actual change is irrefutable. We see life and death, increase and decrease, and rise and decline. The philosophical and scientific discussions are, in fact, related to the explanation of the nature of such changes, their dimensions, divisions and implications.

\section{Change and Motion}

Philosophers talk of two kinds of change: instantaneous and gradual change. Instantaneous change is one which takes place in an 'instant' or in no time. In such a kind of change, we witness the extinction of something and the coming into existence of another. For instance, as a result of burning a piece of wood turns into ashes. Following Aristotle, this process is termed 'generation and corruption' (kawn wa fasad). Something becomes extinct and is replaced by the existence of another. In other words, matter loses a certain form and accepts another form. The other kind of change is gradual. Something starts flowing from an origin to an end, gradually moving away from the origin and getting nearer to the end. This gradual change is called motion (harakat). Gradual change is a flowing and unstable extension, and not a series of generations and extinctions. Although in one's mind motion can be divided into parts, it does not contain actual parts. Rather, it is one continuous reality. Thus, motion is neither composed of, nor reduced to, instantaneous changes or successive rests; as time does not comprise successive instants. Continuity is among the basic elements of motion. A body in motion traverses, in a gradual and continuous manner, all the points between the origin and the end. We cannot think of any such point but that the body must be located in it at some time and pass through it.

\section{Actuality and Potentiality}

Whenever something accepts change, be it instantaneous or gradual, we may talk about actuality and potentiality. Potentiality is possibility and capability, whereas actuality is realization and factuality. Potentiality is related to that which the thing can become, while actuality is what the thing possesses at the moment. The change of $A$ to $B$ indicates that $A$ has the potential of becoming $B$. It is through this change that the potential is realized. Wood essentially contains the potential of turning into ash, a seed can become a plant, and a sperm has the potential of becoming human being. 
Therefore, any kind of change in a thing would imply a transition from potentiality to actuality; or the emergence from the state of potentiality to the state of actuality; or the attainment of a new actuality. Motion, as it is defined, is the gradual emergence of a thing from potentiality to actuality. This is also relative, it does not necessarily imply emergence from absolute potentiality to absolute actuality. Rather, in every given motion, one of the potentials of the given thing attains the actuality suitable to it. Therefore, the moving thing must contain the two aspects of potentiality and actuality, and that is corporeal body. The body with regard to its matter, from the respect that it is disposed to accept a form or a new accident, is regarded as potential; and with regard to the form it contains, is actual. The gradual actualization of a form or a new accident is motion. This is why motion has been defined from olden days as: "Motion is the first perfection of that which is in a state of potentiality qua something in potentiality". A thing which is potential must become actualized in order to attain perfection. To attain actuality is to reach an end. The first step towards the end is motion, or the actual emergence from the state of potentiality. Thus the first perfection acquired by the thing which is potential qua potential, is motion. It can be said, accordingly, that anything which is a compound of potentiality and actuality, or in other words contains the aspects of potentiality and actuality, is subject to motion.

\section{Is Motion Possible?}

As we said, change cannot be denied. But change is more general than motion. Does motion really exist? Some of the Greek philosophers denied motion and considered it impossible. Parmenides, Leucippus and Zeno are among these philosophers. Zeno's well-known paradoxes were expounded precisely in order to refute the possibility of motion. These paradoxes are based on the philosophical theory that a body is a compound of parts which are infinitely divisible, thus every given course consists of infinite disjoint points and moving from one point to another requires traversing infinite points. And since motion requires crossing infinite points, it is impossible. Muslim philosophers generally, like the philosophers of the ancient world who accepted the possibility of motion, have said in response that the divisibility of matter into infinite parts is merely potential, and these points are not actual. What exists in objective reality are not infinite parts, but one finite and continuous thing which is infinitely divisible. Infinite divisibility is something other than the possession of an actual infinity of parts. How- 
ever, some Ash'arite theologians have denied the existence of motion. They denied the existence of motion even in accidents, and considered change to be a sort of renewal of likes (tajadud al-amthal). ${ }^{1}$

There are also differences among those who assert the existence of motion concerning the aspects and precepts of motion. Some have held that there is a universal motion in all things. Heraclitus believes in inclusive motion. He traces the reality of the universe back to fire which is essentially moving.

More recently, some process philosophers, such as Charles Hartshorne, attribute motion even to God. But the concept of an imperfect and changing God is contrary to the God who the philosophers consider to be an absolute, perfect and necessary being. Some do not accept motion in the case of God, but they attribute motion to all contingent beings, be they material or immaterial. The dominant view among the Islamic philosophers is that motion is among the characteristics of body and is restricted to the material world. Motion takes place when something has two aspects of potentiality and actuality, so that its potentiality may turn to actuality. It is only the body which is a compound of form and matter and contains the two aspects of potentiality and actuality.

\section{Motion and the Categories}

Can a material being accept motion in any respect, or does motion occur only in some aspects of the beings in the material world? In order to specify the domain of motion in the material world, the philosophers have brought up the discussion of the categories. According to peripatetic philosophy, categories are seen as the highest genuses which extend over all contingent beings. These categories, based on the dominant view, are of ten kinds: one category of substance and nine categories of accident. Regarding motion in accidents, the accepted view up until the time of Mulla Sadra was that not in all material beings, nor in substances, not even in all

\footnotetext{
${ }^{1}$ According to this view, whenever it appears that motion has taken place, something passes away and is replaced by something else, not that one single thing continues to endure. Their argument is that subsistence is an accident and the occurrence of and accident for an accident is impossible. Thus, an accident cannot persist at two different times. In order to prove the continuous need of the universe for a creator, they made use of the renewal of likes in accidents, for they thought that the effect is in need of the cause only for its coming into being and not for its continuance. On this basis they said that since an accident is always in the state of renewal and a substance is never without accidents, all beings are, therefore, in need of a divine agent.
} 
accidents, but in only some of the accidents does motion take place. They accepted motion in only four categories of accident: quantity (like the growth of a plant), quality (like the change of colour of an apple from green to red), place (such as the movement of a body from one place to another), and position (the change in relation of some parts of a body when compared to other parts, like the movement of a body round itself). Motion in the category of position was added by Ibn Sina. Ibn Sina proves that there is motion in these four categories and provides arguments against motion in substances. ${ }^{2}$

\section{The Objection of Discontinuous Subject and Species}

One of the problems perceived by Ibn Sina for motion in substance is that of the continuity of the subject. Motion is something which occurs to a subject. In other words, motion is the property of the moving. For motion to take place, it must have a fixed subject. The specific form of the subject of motion must endure from the beginning until the end, so that motion may take place in accidents. In case of motion in accidents, the substance is fixed while the accidents change. In the case of motion in substance, there is no fixed subject in which motion occurs or which can be characterized by motion. Motion in substance is equal to movement without a subject. According to this view, the change which occurs in substance must be kinds of generation and corruption in which a body loses a form instantly and accepts a new form thereafter.

Another objection of Ibn Sina to the theory of motion in substance is that if we regard substances as renewing and flowing from imperfection to perfection, then this would imply that in intensifying substantial movement the species should not be enduring. Gradation is not possible in quiddity and substance. The specific quiddities have fixed essences and limits which we demonstrate by logical definitions. The specificity of species is by virtue of its fixed bounds. Now if substance and specific essence becomes subject to gradual change, then that fixed and limited essence would no longer remain stable. But with every substantial change we will have a different species, and it is not that one single species is intensified. In brief, if there is intensification, then the species is no longer stable, and if the species remains stable, then intensification has not taken place.

Ibn Sina's point is that motion in substance is impossible. For if substance were to corrupt it corrupts instantly, and if it were to come into be-

${ }^{2}$ See: Shirazi Sadr Al-Din (Mulla Sadra) 1981, vol. 3. 
ing this also takes place instantly. There is no intermediate stage of perfection between its potentiality and actuality. The reason for this is that substance does not accept intensity or weakness. For if it were so, then in case of intensification, either the species of substance would remain stable or not. If the species endures, then the substantial form has not changed, rather its accidents have changed. But if the substance discontinues, then a substance has gone and another one has come into existence. This implies that in case of intensifying changes, there should exist infinite potential substances between one substance and another. What really takes place in case of substantial form is that one substantial form corrupts and another substantial form comes into being, and there is no intermediate thing between its potentiality and actuality that could be called motion. ${ }^{3}$

Some other philosophers have argued that motion is not possible in substance because substance is an essential part of body, and motion in essentials is impossible. If that which is essential discontinues, the identity of the given thing no longer endures.

\section{Substantial Motion and the Solution of the Problems}

Substantial motion is other than motion in substance. When a person is walking his substance is also moving, but the movement of substance in this state is in the category of place, not in the substance itself. In accidental motions, it is the substance which moves in quantity, quality, place and position. What we mean by substantial motion is the movement of substance in itself.

On what basis can we speak of substantial motion? No doubt in every movement something is lost and something is gained. In accidental motions an accident perishes and another replaces it, but the essence of the given thing is continuous and fixed. But substantial motion requires gradual change in the essence of the moving. Thus substantial motion means a continuous change of a thing, and this necessitates loosing of self or continuous extinction of an essence and the coming into being of other essence. On the other hand, if the essence is not stable, then firstly what occurs is 'generation and corruption' and not motion. Secondly this is something contrary to our perception and inner sense. We believe in some kind of unity for a seed which turns into a young plant, and the young plant which turns into a grown tree. We evidently perceive that someone who was once a child and has now reached the old age, is one and the same per-

\footnotetext{
${ }^{3}$ Ibn Sina 1405 A.H., 98.
} 
son. Every person feels the same by inner sense about himself. Therefore as motion requires change and multiplicity, it also requires some kind of stability and unity of identity.

According to Mulla Sadra substantial motion is not possible if quiddity is taken as fundamental. For quiddity is a unitary and fixed thing, motion in which necessitates change of essence and discontinuity in identity. But on the basis of the fundamentality of existence, motion is but the gradual renewal of existence. Although existence changes because of substantial movement, the essence remains fixed and unity of identity is preserved. For the moving existence preserves its unity and continuity because of the continuous oneness (wahdat al-ittisaliyyah). Continuous unity is identical with personal unity (wahdat al-shakhsiyyah).

Motion in substance, which is only possible on the basis of the fundamentality of existence and its gradation, occurs in the manner of intensity and weakness. The identity of a thing is preserved, but the limits and levels of existence of the thing are in a flow and transformation. With substantial motion, a thing, at every moment, attains a new identity. But because of continuity between the identities, the individual unity of identity is preserved despite the state of motion.

Regarding whether this motion is in need of a subject and if it is then what is it, Mulla Sadra says that since motion is an existent posterior to non-existence, it is in need of a subject. This subject is the matter which attains individuation by an indefinite substantial form, which successively occurs on the prime matter, and accidents. These forms and accidents always change, but the matter is constantly preserved by a form. With this indefinite form, the prime matter is conserved and constituted by an immaterial substance. Its unity is preserved by continuous existence. Be it in substantial or accidental motion, it is the gradation of existence which preserves the unity.

Sometimes it is said that contrary to accidents, which need a subject in which they occur, there is basically no need of a fixed subject in substantial motion other than the substance itself. It is also said sometimes that the subject of substantial motion is the motion itself. Motion is no more than a flow, and the substantial moving is also nothing but that which is essentially in motion. Of course, it is possible to consider some kind of stability for motion whose reality is but elapsing. The stability of motion is in instability and its steadiness in unsteadiness. Motion is instability and unsteadiness of existence, not a subject which is unstable and unsteady. 
In this way the problems of discontinuous subject and species are resolved. The requirement of substantial motion is the necessity of gradation in essentials, and it is through the gradual motion of substance and its gradational identity that a being advances from imperfection to perfection. The objections to it are based on the fundamentality of quiddity. But based on the fundamentality of existence and its gradation, both the subject is preserved and also the enduring subject is something gradational, consisting of levels. Substance does not have a fixed level or grade such that loosing that level would mean loosing the essentials. In substantial motion, the substance is moving from one of its limits to another, and all the bounds which are traversed during the motion are different grades of one single substance.

Therefore a continuous essential substantial motion is proved for the body, which is in fact its very existence. Consequently, the whole corporeal world is in a continuous state of motion, in which stability and rest are not conceivable. Accidental motion is also not restricted to the four categories, rather subsequent to substance, all the categories are moving.

Substantial motion is certainly not perceivable; rather we identify it through rational analysis. The mystics claim to apprehend it by intuition. In order to understand the extension in the unstable dimension of the body, the example of the reflection of a picture on the surface of water is sometimes given. One may think only water is flowing while the picture is still, whereas, in fact, both the water and the picture are in a state of flowing. Sometimes they give the example of the flaming fire whose flames are, instant after instant, in a state of renewal, while the sense perception considers it to be static.

\section{The Arguments for Substantial Motion}

\subsection{Argument through the Causality of Substance In Relation to Accidents}

Motion in accidents cannot be denied. This movement needs a cause. The immediate cause of motion in every body is the nature (tabi'ah) of that thing. Any movement (be it natural movement, voluntary or constrained) must come forth from a faculty located in the nature/essence of a thing, for the cause of something moving must be a moving thing, as the cause of something static must be static. The series of causes which produce change must end with a cause which is essentially moving, and that is the substance of the body. Thus, the body must be essentially moving. 
To put differently, accidents are the effects of substance. A substance has some kind of causal relation to its accidents. Accidents are moving and the cause of the moving must also be moving, that is, the motion and change of accidents must be the effect of motion and change in substance. There must be, therefore, motion in the essence of the substance. In other words, there must be harmony between cause and effect; there is motion in effect (accident), thus there must also be motion in cause (substance).

\subsection{Argument through the Subjection of Accidents to Substance}

The existence of an accident is subject to the existence of that which it characterizes and in which it subsists. Just as the existence of an accident is subject to a substance, similarly the properties of the accident must also be subject to the substance, as what is 'by accident' must revert to that which is 'by essence'. There is motion in some accidents, thus there must also be motion in substance with greater reason. In other words, the existence-initself of an accident is exactly its existence for the substance. Therefore all its existential properties, including motion, must be for the substance.

In this argument it is said that motion in accidents is a proof for motion in substance, but that is not on the basis of the causality of substance in relation to the accident, rather it is based on another perspective of the relation between substance and accident. According to this view, what we attribute to nature are, in fact, not the effects of nature, instead they are among its requirements and subordinates. That is, there is no duality, separation or the relation of cause and effect between nature and accidents, rather there is some kind of unity between the two. Duality and priority and posteriority are necessary in case of cause and effect, but substance and accident do not have such a kind of relation. Accident is the requirement of substance, it is united with it and it is the maximum extent of its existence. Accidents are determinations of substance, and not existents beside it. Therefore the flow in an accident is exactly the same as the flow in substance. If motion is seen in the requirements of the body, then this motion cannot be without being present in the nature of the body. The properties present in accidents are initially present in substance. Thus by accepting motion in accidents, motion in substance cannot be denied. 


\subsection{Argument through Individuation and Unity of Substance and Accident}

Existence is never without individuation (tashakhkhus). To be existent is identical with being individual. Every nature is in need of a factor for its individuation. Most of the philosophers believe that accidents are the cause of the individuation of nature/essence. Without accidents that cause individuation, nature remains something immaterial whose species is confined to a unique individual. And the pure or mere reality of a thing is never repetitive, "a thing in its pureness does not yield to duplication or repetition."

Following al-Farabi, Mulla Sadra is of the opinion that though the annexation of properties, accidents or concepts to a universal and indefinite thing makes it restricted, it does not make it cease to be a universal. The real individuating factor is existence; but at the same time accidents have a role in individuation. They are signs of individuation; marks which indicate the mode of existence of the thing individuated. Since accidents have such a role, their existence is not separate from the thing. The objective reality of a thing is the instance of all properties and characteristics attributed to it. But being an instance of different properties is not homogeneous. A human person is firstly an instance of human being and then an instance of white, black, learned and other accidental qualities. But there is no separation between these properties and the substance, instead the instance of the substance and the accidents is a single reality. As a result, motion in properties is motion in substance, for substance and accident are one thing. In fact, a being in external reality is not a collection of substance, quantity, quality and other accidents as such, rather it is a qualified and a quantified substance where accidents are abstracted from the instantiations of substance.

\subsection{Argument through Actual Change}

Change cannot be denied, be it in accidents or substances. The philosophers before Mulla Sadra considered change in substance to be a kind of 'generation and corruption'. According to this view, in every substantial change, matter looses a form and accepts another form. For instance, water changes to vapour. At times the new form is horizontal to the previous form, yet sometimes the forms are vertical and the latter form is a more perfect state of the former. In the first case, what occurs is an exchange of forms, while in the second case it is a transformation of forms. These philosophers consider 'generation and corruption' as the instantaneous emer- 
gence of a thing from potentiality to actuality. Mulla Sadra is of the opinion that emergence from potentiality to actuality is possible only in a gradual manner, and thus in all cases we have transformation of forms. The water that changes to vapour undergoes a gradual flow and traverses an intermediate level or levels even though we do not perceive such a process. There is no vacuum between water and vapour. Otherwise this would imply that matter should exist, for an instant, without a form and independent of it, whereas such a thing is impossible. Therefore 'generation and corruption' are impossible. As a result, there is continuity between two forms; that is, a single thing is gradually changing. Thus, in every substantial change, there is motion.

To put differently, if we accept actual change in substances, then there is no way but to accept substantial motion. There is no doubt that substances do change, a seed turns into a plant, an embryo into a human being and wood into ash. These changes cannot be instantaneous, for instantaneous change means that matter looses its form in an instant and accepts in an instant another form, and this requires that matter should be for an instant without a form, and this is inadmissible. Matter has no actuality except that of being potential, and its separation from a form is not possible. Therefore, every gradual change is basically a kind of motion, and 'generation and corruption' is not possible. This argument is neither based on accepting the existence of accidents, nor on accepting a specific relation, causal or some other form of dependence, between substance and accident.

\subsection{Argument through the Relation between Actuality and Potentiality}

There exists a factual (waqi'i) relation between that which is potential and that which is actual. In other words, there is continuity between the past and the future of a thing. For example, a seed which becomes a plant has a specific relation to the plant, a relation which it does not have with a human being or a horse. This relation inheres in the two terms of the relation and both of its terms must exist. Two disjoint things have no relation, in the same way that an existent cannot have a real relation with a nonexistent. Thus, this change cannot be a kind of 'generation and corruption'. If there is a relation between a currently present potentiality and a future actuality, then it is because that the future is somehow currently present. A degree of that which is going to be in the future is existing at present, and there is unity and continuity between the present and future existence of a thing. This unity is, of course, accompanied by multiplicity of levels and is 
termed a 'gradational unity'. Change in the substance of a thing or the emergence of a thing from potentiality to actuality together with preserving its unity, is exactly what is meant by substantial motion. This form of argument is from Allamah Tabataba'i.

\subsection{Argument through Time}

If a thing is characterized by a property, then it should not be essentially characterized by the privation of that particular property. Instead it should be, at least, 'unconditioned' (la bi-shart) in relation to it. But sometimes though a thing may be essentially unconditioned to a property, it cannot exist without that property. That is, that property is constantly with it. At times it is otherwise, like in the case of 'heat'. The first kinds of properties always accompany the existence of a thing and are abstracted from its very existence, such as 'space' which is an inevitable requirement of body. Space is not among the constituents of the body's essence, still a body cannot be without space. Time is also like that. A body which moves from one point to another in an hour's time can perform this very motion in two hours or within half an hour; in this case the origin, end and the course of the moving thing are one and the same, but what is different is time. Time is something gradual and flowing. That which is characterized by time is essentially gradual and flowing, and from it, time is abstracted. Time is the amount/measure of the motion of body. Every 'body' has time and duration even if it seems to be static. Time is abstracted from the flowing and renewal of the nature of the body and it is a kind of real extension for things. Therefore a substance which has time must be moving.

\subsection{Argument through Teleology of Nature}

This argument rests on the purposefulness of things. All things are in search of reverting back to their origin and of the attainment of the allTruth; all motions are directed towards that Being. Nature has a purpose and every potentiality is aiming for a goal. If the change from potentiality to actuality or the change of forms were to be of the kind of 'generation and corruption', such that matter were to loose a form and accept another form, then flowing towards a goal would not be possible; for the form would no longer exist to pursue the goal. Also there would be no continuity between the successive forms to provide unity to them. We can only talk of the purposefulness of a thing when, throughout this change, one single 
form aims towards a goal. Otherwise nature cannot be said to have a purpose even if supernatural agents were after a purpose in nature. In fact, purpose is for the form and not matter; though it is possible to attribute purpose to the matter subsequent to that of the form. Thus, there must be a single flowing form so that purpose can be attributed to it. If every 'body' has a purpose, then it must be essentially flowing towards that purpose. In this explanation, the successive forms are a kind of attaining successive forms and not losing a form and gaining another form. ${ }^{4}$

\section{The Consequences and Implications of Substantial Motion}

Mulla Sadra does not only add a category out of the different categories to the moving things. Rather based on the most fundamental principle of his philosophy - that is, the fundamentality of existence, and subsequent to that, the gradation of existence-he is in fact presenting a new concept of cosmology in which he looks from a completely new perspective to such concepts as existence, quiddity, substance, accident, the relation between them, motion, generation and creation.

\subsection{General Motion}

The theory of substantial motion does not only prove that there is movement in one category, rather with the establishment of motion within bodily substance, it follows that the whole of the material world is in motion. If substance is flowing - and strictly speaking if its nature is nothing other than the actual flow-then all accidents also would be flowing. For accidents are the states of a substance and it is not possible that substancewhich is the subject, source, origin, or cause of accidents-should be moving while accidents remain static. Matter is not something for which motion occurs, rather it is the moving. Motion is nothing but the flow and this is exactly the reality of bodily substance. Motion inheres with potentiality and actuality, and with an agent and a recipient. That which accepts motion must end up with sheer potentiality which is prime matter, while the agent of motion must revert back to absolute actuality, as its purpose is also to attain absolute actuality. Therefore, motion begins from matter and culminates in what is immaterial. Of course, the possibility of the existence of motion in objective reality is not based on the acceptance of prime matter.

\footnotetext{
${ }^{4}$ See: Motahhari 2005, 502-554.
} 
Even those who have rejected the existence of prime matter believe in motion, including substantial motion.

Since motion is gradual existence, and changing or becoming is essential to it, such an existence naturally embraces non-existence and contains within itself existence and non-existence, unity and multiplicity, potentiality and actuality, and perfection and imperfection. As a result, the necessary being who is absolute existence, unity, actuality and perfection, is beyond every change and motion.

\subsection{The Unity of the Material World}

According to Mulla Sadra prime matter is created ex nihilo, not through previous matter, while every other material being is preceded by matter. The immaterial agent is the creator of forms and the prime matter which accepts them. Prime matter does not exist without form as form also does not exist without prime matter. Matter is but potentiality and receptivity, while actuality is in need of a creative agent which is not matter. The existing world is one continuous unit which is moving towards a purpose.

The unity of beings and their coming into existence one from another is a demonstration of a flow of reality towards a purpose. Quiddities come and go, but material existence continues to subsist. It comes into existence as it passes away and it is renewed as it gets worn out, for it is flowing and extended. Every level is a product of the former level and, at the same time, a preparatory stage for the next level. Therefore, in the same manner that the material world contains multiplicity, it also procures a fundamental unity, a unity which brings together all multiplicity and assembles all the apparently scattered things as parts and grades of one single reality.

\subsection{The Perfection of the Material World}

Perfection has been said to be the attainment of new forms by matter, or wearing (a form) after wearing (lubs ba'd al-lubs). Motion is in a state of acquiring perfection in so far as it is the emergence of potentiality to actuality. Material being attains, as result of motion, more intense and higher kinds of potentiality and actuality. The corporeal world is in constant motion and change. Minerals are the primary forms followed by inanimate forms, plants, animals and finally comes the human being. The human soul also comes into existence as result of change in matter and moves towards becoming immaterial. There is no end to the ascending movement of the 
human soul, rather it attains elevation as result of human actions until it reaches the stage of 'meeting with Allah'. Thus matter moves in an ascending manner from the lowest of the grades of existence to its highest level. The human being is the most sublime product of substantial motion. The human soul after attaining immateriality enters the realm of eternal beings.

\subsection{From Physics to Metaphysics}

One of the constituents of motion is its agent. If motion dwells in the essence and core of things, then what is its agent? Motion, according to Mulla Sadra, does not happen to the body, rather it is identical with the body in existence and is considered as one of the necessary dimensions and an essential requirement of the nature of the body. Since motion has no independent existence from the body, its agent is exactly that of the body. That which brings a body into existence also brings motion into being; of course not with a separate creation, for creating the body is exactly creating the motion, as it is exactly creating the geometric dimensions of the body. According to this view, it is not that the body is independent in its essence of a divine cause and is only dependent on such a cause for its motion, but this need of it for a cause is much deeper; the body is in need of a divine cause for its actual existence. The divine cause, by bestowing existence on the body, also grants it motion. The making of the body is exactly the making of the motion. As we will mention later, in so far as substantial motion indicates the temporality (huduth) of this world, it is one way of proving the existence of a creator. Basically the Aristotelian argument of the first mover is inadequate and questionable without the acceptance of substantial motion. Some of the philosophers are of the opinion that the immaterial being, apart from being the creator of the moving material existent, it is also the preserver of the unity and continuity of such scattered and flowing being.

Contrary to the view of Suhrawardi, motion is not among the categories. Categories are the highest genus of quiddities, while motion is a form of existing: a weak and flowing existence which is apart from the categories, in the same manner that stability is another form of existing. Since motion is among the concomitants of existence and not among the accidents of body or the material world, the discussion about motion is transferred from the natural sciences to metaphysics. 


\subsection{The Relation of the Changeable to the Unchanging}

The changing effect has a changing cause. How can the changing matter be the effect of that which is unchanging and beyond matter? The response of Mulla Sadra is that since substantial motion is exactly the existence of the moving thing, the making ( $\mathrm{ja}$ ' $l$ ) and creation of motion is not something apart from the creation of the moving thing. In other words, the creation of motion is not a composite creation (ja'l ta'lifi), rather it is a simple creation (ja'l basit). The very reality of the thing which is its existence is created, not its change. God does not give motion to the world, rather He gives existence to it. Thus, God is the cause of existence and not the cause of motion and renewal. The corporeal existent is flowing in its essence and renewal is essential to it, and that which is essential does not need a cause, just as stability is exactly the existence of the stable thing.

The immediate cause of accidental motions must be something changing; for the cause of that which is changing must also be changing, the giver of change must possess change. Such kinds of motions have no necessary and intrinsic relation with their subject, instead their relation is one which is possible and accidental. But in substantial motion, where movement is exactly the same as the moving thing and its relation to the moving thing is necessary and essential, the cause of the moving is not a moving thing; for the cause does not give motion, what it gives instead is existence. The maker of salt or honey does not necessarily have to be salty or sweet. Allah did not put together apricots, rather He gave apricots existence. Thus the material substance itself-which is no different than its motion-is intermediate between the changing and the unchanging.

\subsection{The Interpretation of Time}

According to Mulla Sadra's theory of substantial motion, time is not a thing; it is neither substance nor accident. Time is an analytic accident of motion while motion is an analytical accident of body. Time has no independent identity apart from existing things, in the same way that motion also has no such identity. In the manner that body has three static dimensions, it also has a fourth dimension which is instability, from which time is abstracted. The flowing and renewing state of a thing is what is called motion. Time is actually a description of this renewing and flowing dimension of the natural substance. The relation of time to the flowing dimension of the corporeal existent is like the relation of a three-dimensional geomet- 
rical form to a physical mass in so far as it has the three dimensions. Time is the gradual and essential extent of a body in relation to its intrinsic priority and posteriority, while the three dimensions (length, width and depth) are the spatial and simultaneous extent of a body at an instant. Time is the extent of motion and we have time according to the number of motions. All existents have time whether they apparently seem to be in motion or otherwise. The time of each body is subordinate to the substantial motion of that body and it is abstracted from the mode of its existing. Thus, things are not in time; and we can say, however roughly, that time is within the existing things. The general time which is measured after the movement of the earth around its orbit or other planets is one among many 'times'. God and the immaterial beings are unchanging and without motion, and therefore they are without time. It is based on this that their eternity-which is another expression for their being beyond time- - becomes understandable.

\subsection{The Temporal Creation of the World}

Is the material world temporal or eternal? Mulla Sadra proves the temporality of the world based on substantial motion and by the creation of the world in time together with its continuous renewal. The world is, at every instant, in a state of temporal renewal; the whole world is also temporal and in need of a creator. But, at the same time, we should not be after a temporal beginning point for the creation of the world. There exists no time before the creation of the world so that its creation may take place within it. Mulla Sadra brings together priority and posteriority and believes that essential temporal origination is compatible with temporal preeternity. The world has always been with the property of being temporally originated. Renewal and 'becoming' are among the essential requirements of the material world. Based on this Mulla Sadra is of the opinion that the whole of the corporeal world, including both substances and accidents, the simple and compound entities, whether celestial or earthly, are all in motion. They are all in a state of gradually coming into existence and are never the same at two different instants. The very foundation of this world is on motion while gradual change is right within the essence of the existing things. The matter of this world accepts a variety of forms and thus successively attains new actualities. The existence of bodies is a renewing existence while change is its form. Every form is posterior to its nonexistence in time. Eternity necessitates immutability and is incompatible 
with matter in whose essence lie renewal and flowing. The corporeal world is wholly in a state of continuous motion.

\subsection{Body and Soul}

According to Mulla Sadra soul does not exist prior to the body. Rather it comes into being with the intensifying (takaamuli) change of body, and attains perfection as a result of substantial change. It is separated from the body after it becomes immaterial and continues to subsist immaterially. The need of soul for body is not only because of its actions, rather it is dependent on body for its actual existence. Thus, the soul is material in origin and immaterial in continuity. As a result of the perception of intellects, the soul attains intensification; it moves towards perfection and it turns to become the intellect, the intelligent and the intelligible, all of which are but one reality. If we do not accept substantial motion, then we can no longer consider an intensifying soul as substance. According to this view, the differences between the souls of a child, a philosopher, an aged mystic and even that of a prophet are to be found only in accidents which are apart from the essence. But according to the doctrine of substantial motion, the differences between them lie at the core of their essences, and a single individual would attain, as a result of motion, one gradational form. The beliefs, intentions and actions of a person play an important role in the constitution of the soul and in its attainment of the stages of perfection. Our decisions, beliefs and actions are shaping our existence. Our existence is nothing but the objective embodiment of our achievements.

\subsection{Divine Wisdom and Resurrection}

As motion and change reveal that there is a beginning to the material world, they also signify that the world must come to an end. That which is eternal cannot be changing. That which changes has a beginning and an end. The movement of matter has an immaterial purpose which is entering into the next world and returning back to God. "To Allah is the return," (Qur'an 42: 53). Based on a particular analysis, Mulla Sadra also argues for some kind of corporeal resurrection. The intensifying motion of the world and the movement of matter from primary elements to a perfect human being, signifies the purposefulness of the world and indicates the knowledge, wisdom and the will of the Creator. This in turn requires life 
and subsistence after death as it also necessitates the resurrection and eternity.

In this manner, based on the fundamentality of existence, Mulla Sadra concludes that there is substantial motion; and this enables him to present a new interpretation of the world and to resolve such problems as that of the reality of existence, the unity and reality of the natural world, the changing and the unchanging and the relation between the two, temporality and eternity and their relation, the problem of time, the corporeal origin of soul and its intensifying movement, and the doctrine of the resurrection.

\section{REFERENCES}

Ibn Sina 1405 A.H. Al-Shifa, al-Tabi 'iyyat, vol. 1, Qom: Najafi.

Motahhari, M. 2005 Majmu'a-e Athaar (Collected Works), vol. 11, Tehran: Sadra.

Shirazi, Sadr al-Din 1981 Al-Asfar, vol. 3, Beirut: Dar Ihya al-Turath al-Arabi. 
